\title{
Thoracic Disc Herniation Presenting with Predominant Abdominal Pain
}

\section{Hiroyasu Fujiwara ${ }^{1 *}$, Takashi Kaito², Takahiro Makino ${ }^{1}$ and Kazuo Yonenobu ${ }^{3}$}

${ }^{1}$ Department of Orthopaedic Surgery, National Hospital Organization, Osaka Minami Medical Center, Japan

${ }^{2}$ Department of Orthopaedic Surgery, Osaka University Graduate School of Medicine, Japan

${ }^{3}$ Graduate School of Health Care Sciences, Jikei Institute, Japan

\begin{abstract}
Introduction: The incidence of symptomatic thoracic disc herniation (TDH) is quite low, and most patients present with either radiculopathy as pain in the chest wall or thoracic myelopathy involving the lower extremities. However, not only these typical symptoms, but also various other symptoms pointing to other general diseases can be the sole presenting complaints. We describe a rare case in which a patient presented with predominant abdominal pain caused by thoracic disc herniation.
\end{abstract}

Materials and Methods: Retrospective data analysis and review of the literature.

Results: A 45-year-old man experienced sudden onset of abdominal pain and presented to our internal medicine outpatient clinic. Due to obvious concomitant paraplegia, he was referred to our department. Physical examination revealed spastic paraplegia below the T10 dermatome level. Thoracic magnetic resonance imaging showed disc herniation at the T9-10 level. Herniotomy was performed, and abdominal pain completely disappeared immediately postoperatively.

Conclusions: Although the anatomical location within a given axial cross-section of the spinal cord where visceral pain is processed is still controversial, some reports have defined the visceral nociceptive pathway as ascending in the midline of the dorsal columns, particularly in the nucleus gracilis. Damage to this pathway seems to represent a cause of abdominal pain with TDH. Further investigations in this area are required to elucidate the exact mechanisms involved. Surgeons should be aware of atypical presentations of TDH, to prevent misdiagnosis and progression to irreversible myelopathy.

Keywords: Thoracic disc herniation; Abdominal Pain; Myelopathy; Nucleus gracilis; Greater splanchnic Nerve; Dorsal column; Visceral pain

\section{Introduction}

The incidence of symptomatic thoracic disc herniation (TDH) has been reported as 1 per million per year [1]. Most patients present with either radiculopathy as pain in the chest wall or thoracic myelopathy involving the lower extremities. However, various other symptoms suggestive of other diseases such as coronary artery disease, aorta dissection, or visceral disease can be the sole presenting complaints [15]. Such confusing symptoms may lead to either unnecessary operations based on misdiagnosis or progressive neurological compromise. To avert such mishaps, an understanding of the atypical presentations of TDH is necessary. We describe herein a rare case of a patient who presented with predominant abdominal pain caused by TDH.

\section{Case Report}

A 45-year-old man with a history of ulcerative colitis 16 years earlier presented with a 1-month history of melena. One morning when he woke up, he noticed weakness in the lower extremities. One hour later, he experienced sudden acute pain in the right hypochondrium and could not keep standing. He visited the Department of Digestive Organs at our institution the same day because of predominant abdominal pain and melena. As no abdominal tenderness with muscular defense or non-urgent laboratory data results were evident and the primary gastroenterologist noticed the concomitant paralysis in the lower extremities, he was brought to the Department of Orthopedic Surgery. He could maintain balance in a sitting posture, but could not keep a standing position or and keep bent-over position because of abdominal pain. Neurological evaluation showed hyperreflexia of both lower extremities. Pinprick sensation was decreased (6/10) below the level of the right T10 dermatome, but touch sensation remained intact. Muscular weakness was seen in the iliopsoas (2/2), quadriceps $(4 / 4)$, tibialis anterior (4/3), extensor hallucis longus $(3 / 2)$, gastrocnemius
(3/3), and gluteus medius (3/3) on manual muscle testing. When the patient was first seen, he was not aware of any bladder or bowel disturbances, but bladder and bowel dysfunction became evident with urinary retention after $12 \mathrm{~h}$, and residual urine was found on urethral catheterization. The Japanese Orthopaedic Association (JOA) score for thoracic myelopathy (maximum, 11) (Table 1) [6] was 2 points (motor function of lower extremity, 0 ; sensory function of lower extremity, 1 ; sensory function of trunk, 1; bladder function, 0), and Frankel grade [7] was C. Radiography of the thoracic spine demonstrated spondylotic changes and disc space narrowing at the T9-10 level (Figure 1). Magnetic resonance imaging (MRI) showed disc herniation at the T9-10 level (Figure 2a) and axial sections showed compression of the thoracic spinal cord from the left side (Figures $2 b$ and $2 c$ ). Although no definitive cause of the abdominal pain was clear, emergency surgery for TDH was performed due to obvious progressive myelopathy. T9-10 partial laminectomy and facetectomy on left side using a high speed drill was performed to achieve resection of the disc herniation. The herniation was extruded from the posterior longitudinal ligament and was excised from the dura mater without difficulty. Fortunately, complete relief of abdominal pain was obtained immediately postoperatively, with concomitant neurological recovery. On postoperative day 7 , the

*Corresponding author: Hiroyasu Fujiwara, Department of Orthopaedic Surgery, National Hospital Organization, Osaka Minami Medical Center, 2-1 Kidohigashi, Kawachinagano, Osaka 586-8521 Japan, Tel: +81-721-53-5761; Fax: +81-721-538904: E-mail: MLD03108@nifty.com

Received May 03, 2013; Accepted November 04, 2013; Published November 07, 2013

Citation: Fujiwara H, Kaito T, Makino T, Yonenobu K (2013) Thoracic Disc Herniation Presenting with Predominant Abdominal Pain. J Spine 2: 144. doi:10.4172/21657939.1000144

Copyright: ( 2013 Fujiwara H, et al. This is an open-access article distributed under the terms of the Creative Commons Attribution License, which permits unrestricted use, distribution, and reproduction in any medium, provided the original author and source are credited. 
Citation: Fujiwara H, Kaito T, Makino T, Yonenobu K (2013) Thoracic Disc Herniation Presenting with Predominant Abdominal Pain. J Spine 2: 144. doi:10.4172/2165-7939.1000144

Page 2 of 3

\begin{tabular}{|l|c|}
\hline Category & Score (Point) \\
\hline Motor function & \\
\hline Lower extremity & \\
\hline Unable to stand and walk by any means & 0 \\
\hline Unable to walk without a cane or other support on a level & 1 \\
\hline Walks independently on a level but need support on stairs & 2 \\
\hline Capable of fast but clumsy walking & 3 \\
\hline Normal & 4 \\
\hline Sensory function & \\
\hline Lower extremity & \\
\hline Apparent sensory disturbance & 0 \\
\hline Minimal sensory disturbance & 1 \\
\hline Normal & 2 \\
\hline Trunk & 0 \\
\hline Apparent sensory disturbance & 1 \\
\hline Minimal sensory disturbance & 2 \\
\hline Normal & \\
\hline Bladder function & 0 \\
\hline Urinary retension and/or incontinence & 1 \\
\hline Sense of retension and/or dribblind and/or thin stream and/ & 2 \\
\hline or pollakiuria & 3 \\
\hline Urinary retardation and/or pollakiuria & \\
\hline Normal & \\
\hline Ta & \\
\hline
\end{tabular}

Table 1: Japanese Orthopaedic Association (JOA) scores for thoracic myelopathy.

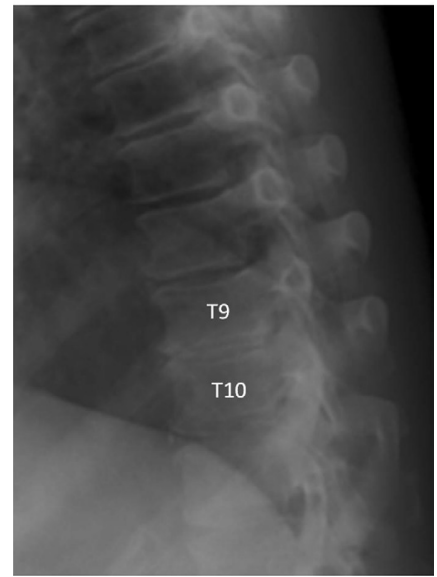

Figure 1: Radiography of the thoracic spine, demonstrating spondylotic changes and disc space narrowing at the T9-10 level.

patient showed no bladder or bowel disturbances, and independent gait. Postoperative MRI demonstrated decompression of the spinal cord and nerve root (Figures 2d-f). Follow-up neurological examination at 3 years postoperatively showed just only dysesthesia in both feet but no other abnormal findings. The JOA score had recovered to 10 (4-1-2-3), and Frankel grade had also recovered to D., and no recurring symptoms of the disc herniation was evident.

\section{Discussion}

This patient showed predominant abdominal pain caused by TDH that was able to be promptly diagnosed and treated due to the concomitant severe myelopathy. TDH is commonly asymptomatic and the natural history has been reported to show little change in size and to remain asymptomatic [8]. Even in cases of symptomatic TDH, spontaneous resolution has been reported [9]. However, in rare settings, TDH presents with atypical symptoms such as chest or abdominal pain. According to several reports, patients with TDH who present with symptoms mimicking chest or abdominal pain were treated unsuccessfully because of delayed diagnosis $[3,10]$.

Although spinal cord disorders can be a cause of abdominal pain, the anatomical location within a given axial cross-section of the cord where visceral pain is processed remains controversial [11-16]. Visceral and somatic afferent fibers may attribute to different spinal locations, including dorsal columns, spinothalamic and spinocerebellar tracts, and the dorsal and ventral horns. Kim and Kwon [17] reported thoracic midline dorsal column myelotomy at the C7-T2 level as a successful treatment for severe visceral pain due to advanced stomach cancer. Nauta et al. [18] reported thoracic midline dorsal column puncture at the T8 level as an effective treatment for severe lower abdominal pain due to uterine cancer. They defined the visceral nociceptive pathway as ascending in the midline of the dorsal column, particularly in the nucleus gracilis. Further investigation in this area is required to elucidate the exact conducting pathways.

We deduced the following two mechanisms for predominant abdominal pain in this case. First, bony compression such as by a contralateral superior facet joint or pedicle could have induced contralateral friction radiculitis [19], because the symptom was contralateral to compression in this case. In addition, for ipsilateral symptoms, Jooma et al. [20] noted that radiculopathy associated with lower thoracic (T8-T12) lesions can present as surface or visceral abdominal pain. Simeone [21] reported that radiculopathy at the T710 level can be misdiagnosed as cholelithiasis and that at the T10-12 level can be misdiagnosed as acute appendicitis. Second, compressive myelopathy could have induced hypoperistalsis through disorder of the greater splanchnic nerve, or hyperperistalsis through relative parasympathetic stimulation. Ozaki et al. [22] reported that cutting the greater splanchnic nerve led to inhibition of the pathway of hyperalgesia in experimentally created gastric ulcers in rats.

On the other hand, in terms of diagnostic methods for differentiating between myelopathy and radiculopathy, Stetkarova et al. [23] recommended electrophysiological examinations such as electromyography (EMG). They reported lateral disc herniation causing compression of a thoracic root associated with unilateral segmental paresis of the abdominal wall. In that case, partial denervation and a neurogenic pattern in the oblique abdominal muscle and positive sharp waves in the multifidus muscle on needle EMG confirmed axonal root impairment, whereas somatosensory and motor evoked potentials were
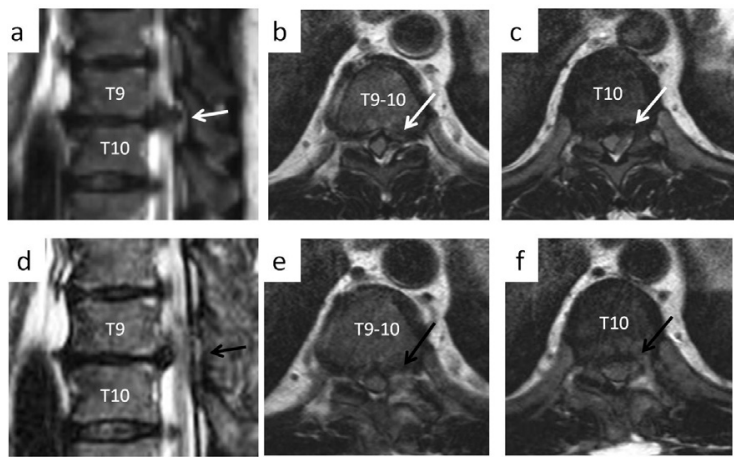

Figure 2: Magnetic resonance imaging (MRI) on T2-weighted image reveals disc herniation at the T9-10 level in the left parasagittal section (a) and compression of the thoracic spinal cord at the same level in the axial section $(b, c)$ indicated by white arrows. Postoperative MRI demonstrates no compression of the spinal cord by any masses (d-f) indicated by black arrows. 
Citation: Fujiwara H, Kaito T, Makino T, Yonenobu K (2013) Thoracic Disc Herniation Presenting with Predominant Abdominal Pain. J Spine 2: 144. doi:10.4172/2165-7939.1000144

within normal limits and excluded spinal cord involvement. In the present case, EMG testing could not be performed because the patient required emergency surgical treatment due to severe progressive myelopathy.

Treatment of herniated thoracic discs includes both operative and nonoperative options. Although symptomatic TDH is uncommon, a missed or delayed diagnosis can be problematic, potentially resulting in not only unnecessary surgical procedures based on misdiagnosis, but also progressive myelopathy and permanent paralysis. Thoracic disc herniation thus needs to be kept in mind as a cause of symptoms mimicking other non-spinal disorders. In addition to thorough neurological examination, MRI and electrophysiological examinations are helpful in achieving earlier diagnosis.

\section{References}

1. Arce CA, Dohrmann GJ (1985) Herniated thoracic disks. Neurol Clin 3: 383392.

2. Epstein JA (1954) The syndrome of herniation of the lower thoracic intervertebral discs with nerve root and spinal cord compression. A presentation of four cases with a review of literature, methods of diagnosis and treatment. J Neurosurg 11: $525-538$

3. Whitcomb DC, Martin SP, Schoen RE, Jho HD (1995) Chronic abdominal pain caused by thoracic disc herniation. Am J Gastroenterol 90: 835-837.

4. Wilke $A$, Wolf $U$, Lageard $P$, Griss $P(2000)$ Thoracic disc herniation: a diagnostic challenge. Man Ther 5: 181-184.

5. Xiong Y, Lachmann E, Marini S, Nagler W (2001) Thoracic disk herniation presenting as abdominal and pelvic pain: a case report. Arch Phys Med Rehabil 82: $1142-1144$

6. Matsumoto M, Chiba K, Toyama Y, Takeshita K, Seichi A, et al. (2008) Surgical results and related factors for ossification of posterior longitudinal ligament of the thoracic spine. A multi-institutional retrospective study. Spine 33: 10341041.

7. Frankel HL, Hancock DO, Hyslop G, Melzak J, Michaelis LS, et al. (1969) The value of postural reduction in the initial management of closed injuries of the spine with paraplegia and tetraplegia. I. Paraplegia 7: 179-192.

8. Wood KB, Blair JM, Aepple DM, Schendel MJ, Garvey TA, et al. (1997) The natural history of asymptomatic thoracic disc herniations. Spine (Phila Pa 1976) 22: $525-529$
9. Morandi X Crovetto N Carsin-Nicol B Carsin M, Brassier G (1999) [Spontaneous disappearance of a thoracic disc hernia]. Neurochirurgie 45 155-159.

10. Rohde RS, Kang JD (2004) Thoracic disc herniation presenting with chronic nausea and abdominal pain. A case report. J Bone Joint Surg Am 86-86A: 37981.

11. Al-Chaer ED, Lawand NB, Westlund KN, Willis WD (1996) Visceral nociceptive input into the ventral posterolateral nucleus of the thalamus: a new function for the dorsal column pathway. J Neurophysiol 76: 2661-2674.

12. Hancock MB, Foreman RD, Willis WD (1975) Convergence of visceral and cutaneous input onto spinothalamic tract cells in the thoracic spinal cord of the cat. Exp Neurol 47: 240-248.

13. Hirshberg RM, Al-Chaer ED, Lawand NB, Westlund KN, Willis WD (1996) Is there a pathway in the posterior funiculus that signals visceral pain? Pain 67 291-305.

14. Mayer EA, Raybould HE (1990) Role of visceral afferent mechanisms in functional bowel disorders. Gastroenterology 99: 1688-1704.

15. Mayer EA, Gebhart GF (1994) Basic and clinical aspects of visceral hyperalgesia. Gastroenterology 107: 271-293.

16. Rigamonti DD, Hancock MB (1978) Viscerosomatic convergence in the dorsa column nuclei of the cat. Exp Neurol 61: 337-348.

17. Kim YS, Kwon SJ (2000) High thoracic midline dorsal column myelotomy for severe visceral pain due to advanced stomach cancer. Neurosurgery 46: 85-90.

18. Nauta HJ, Hewitt E, Westlund KN, Willis WD Jr (1997) Surgical interruption of a midline dorsal column visceral pain pathway. Case report and review of the literature. J Neurosurg 86: 538-542.

19. Hasegawa T, Imai Y, Katsuno R, Ohnaru K, Saeki T, et al. (2005) Lumbar radiculopathy contralateral to the side of lumbar disc herniation. Kawasak Medical Journal 31: 47-54.

20. Jooma R, Torrens MJ, Veerapen RJ, Griffith HB (1983) Spinal disease presenting as acute abdominal pain: report of two cases. Br Med J (Clin Res Ed) 287: 117-118.

21. Simeone FA (1999) Intradural tumors. In: Herkowitz HN, Garfin SR, Balderston RA, eds. The spine. Philadelphia: WB Saunders

22. Ozaki N, Bielefeldt K, Sengupta JN, Gebhart GF (2002) Models of gastric hyperalgesia in the rat. Am J Physiol Gastrointest Liver Physiol 283: G666-676.

23. Stetkarova I, Chrobok J, Ehler E, Kofler M (2007) Segmental abdominal wal paresis caused by lateral low thoracic disc herniation. Spine (Phila Pa 1976) 32: E635-639. 